\title{
CINE ESPAÑOL: ELEGY DE ISABEL COIXET
}

\section{SPANISH CINEMA: ELEGY BY ISABEL COIXET}

Beatriz Peña Acuña: Universidad San Antonio. Murcia (España) beatriz-pa@gmail.com

Antonio Miguel Conesa Nieto: Universidad de Murcia (España) m.conesanieto@um.es

\section{CURRÍCULUM VITAE}

Licenciada en Filología, Diplomada en Humanidades y Periodista. Profesora de "Observación sistemática y análisis de contextos" en Magisterio Infantil, "Trabajo fin de Grado" en Turismo y "Comunicación interna" a posgrados. Profesora del Cuerpo de Tutores de la Universidad Católica San Antonio. Ha participado en diversos congresos internacionales de innovación educativa como International Conference of Education and Innovation e International Technology, Education and Development Conference con varias ponencias en inglés y ha publicado artículos concernientes a la educación en vasrias revistas científicas. Ha publicado material para docentes de Secundaria para la editorial on-line de Santillana: profes.net. Ha publicado un manual sobre "Métodos de observación aplicados a las Ciencias Sociales y la Educación" dirigido a alumnos de Magisterio.

Licenciado en Historia por la Universidad de Murcia (España). 


\section{RESUMEN}

Este artículo investiga cómo la directora Isabel Coixet ha llevado a cabo la adaptación de la novela El animal moribundo del escritor norteamericano Philip Roth al largometraje Elegy (2008). Pretende a su vez analizar cómo retrata la sociedad norteamericana al comparar el estatus social de los protagonistas de Mi vida sin mí y Elegy.

\section{PALABRAS CLAVE}

Coixet - Roth - Adaptación - Elegy - Mi vida sin mí - Sociedad Norteamericana

\section{ABSTRACT}

This article investigates how the director Isabel Coixet has achieved the adaptation of the novel The dying animal of the American writer Philip Roth to the film Elegy (2008). It aims to examine how the Catalonian director portrays the American society by comparing the social status of the protagonists of My Life Without Me and Elegy.

\section{KEY WORDS}

Coixet - Roth - Adaptation - Elegy - My Life Without Me - American Society

\section{ÍNDICE}

1. Introducción

2. Notas biográficas de Isabel Coixet

3. Notas filmográficas de Isabel Coixet

4. El caso de la adaptación de El animal moribundo a la película Elegy (2008) 
5. Comparación del contexto social presentado en Mi vida sin mí (2002) y en Elegy (2008)

5.1. Belle epoque

5.2. Años 20

5.3. La sociedad de consumo

5.4. Nuevo orden mundial

5.5. Contexto y comparación de las películas: Mi vida sin mí y Elegy

6. Conclusiones

7. Bibliografía

TEXTO:

\section{Introducción}

Este artículo pretende facilitar en primer lugar un marco histórico para que el lector se familiarice con la obra de Isabel Coixet, una directora que despunta en el escenario español e internacional. En segundo lugar, se pretende analizar la película Elegy con más detenimiento para descubrir los matices que ha aportado Coixet. Esta cinta se caracteriza entre sus otras obras por la peculiaridad de que no está basada en un guión original de la cineasta como es costumbre, sino que se trata de una adaptación de una novela popular: El animal moribundo de Philip Roth con guión de Nicolas Meyer. En tercer lugar, se compara la sociedad que refleja esta cinta con un largometraje anterior Mi vida sin mí. Para ello se detalla un breve recorrido histórico de la sociedad norteamericana. 


\section{Notas bibliográficas}

Isabel Coixet i Castillo nace en Sant Adrià de Besòs (Barcelona) en 1962. En 1979 redacta guiones de comic y publica escritos sobre cine en las revistas Sal común y Fotogramas. Se forma en el terreno publicitario. En 1983 finaliza Historia Contemporánea en la Universidad de Barcelona (Borau, 1998: 238). Es una mujer polifacética: directora, productora y guionista cinematográfica. Ha sido además fundadora y directora creativa de la agencia Target y de la productora Eddie Saeta, en la que ha obtenido los más prestigiosos premios por sus productos en publicidad. Crea la productora Miss Wasabi Films en el año 2000, desde donde ha producido destacados videoclips y documentales. Otra de sus facetas es la dirección de teatro en la que debuta con 84 Charing Cross Road, basada en una obra de la estadounidense Helene Hannf. Está considerada como una cineasta sobresaliente entre los críticos, y ocupa un lugar en los principales diccionarios y manuales de la historia del Cine español.

\section{Notas filmográficas}

Su filmografía hasta la fecha es la siguiente (datos IMBD):

Mapa de los sonidos de Tokyo (2009)

Elegy (2008)

Invisibles (capítulo Cartas a Nora) (2007)

La vida secreta de las palabras (The Secret Life of Words) (2005)

!Hay motivo! ("La Insoportable Levedad Del Carrito De La Compra") (2004)

Mi vida sin mí (My Life Without Me) (2003)

A los que aman (1998)

Cosas que nunca te dije (Things I Never Told You) (1996)

Demasiado viejo para morir joven (1989) 
Mira y verás, cortometraje, (1984)

Se destacarán algunos hitos en su recorrido filmográfico. Su primer largo Demasiado viejo para morir joven es una historia de tres personajes que intentan sobrellevar los dilemas cotidianos en un ámbito urbano. En Cosas que nunca te dije rueda una comedia romántica en inglés con actores norteamericanos. Caparrós Lera cita esta película en su momento y destaca a Isabel Coixet entre otros cineastas como Gracia Querejeta. El académico ya se autocuestiona sobre si estos cineastas conformarán el cine que disfrutamos hoy en día: “¿Será ese el futuro del cine español?”(Caparrós, 1999: 197). Con los hechos la catalana irá contestando a esta pregunta que, en efecto, así es, en lo que se refiere a ella, se está cumpliendo.

En los 90 esta directora se da a conocer más con A los que aman para el público español. Despunta en una época junto a otros directores jóvenes que prometen mucho como Iciar Bollaín, Benito Zambrano, Achero Mañas, etc. Con su filme siguiente Mi vida sin mí, se reafirma con la crítica a su favor. Es galardonada con el premio Nacional de Cine y Audiovisual de Cataluña. Es en La vida secreta de las palabras en 2005 donde esta cineasta realmente reluce. Unos meses más tarde que en España, esta película fue estrenada con muchas expectativas en Nueva York donde la directora consigue atraer la atención de la academia norteamericana. Dicho sea de paso, contaba con la simpatía del público neoyorkino porque en la cinta actuaba el actor Tim Robbins, actor muy popular en la ciudad en la que sigue representando teatro. A tenor de lo dicho, este largometraje consiguió el Goya de 2006 en las categorías de Mejor Película, Mejor Director, Mejor Guión Original y Mejor Diseño de Producción, el Sant Jordi y el Fotogramas de Plata, entre otros muchos premios.

A continuación filmaría la película que nos ocupa Elegy. Uno de los primeros aciertos del largometraje que se subrayan es el acierto del castin. En esta cinta la recién oscarizada actriz española Penélope Cruz aparece como Consuelo Castilla, 
protagonista junto con Ben Kingsley, uno de los actores más reputados por su trayectoria en cintas emblemáticas como Ghandi (R Attenborough, 1982) por la que recibió un Óscar, o La lista de Schindler (S. Spielberg, 1993). Este actor cuenta en su haber nada más que veintiséis premios y treinta y seis nominaciones. La naturalidad que ambos despliegan en su interacción amorosa no se improvisa, ambos cuentan con mucha experiencia en rodajes, pues la actriz española ha desarrollado cuarenta y seis papeles en largometrajes (datos IMBD). Penélope obtuvo por su actuación dos premios en la categoría de mejor actriz en Los Ángeles Film Critics Association Awards (2008) y en Santa Barbara International Film Festival (2009).

Son muy interesantes las declaraciones de los actores en el documental que aparece en el DVD de la película porque testimonian cómo ha sido su trabajo con Isabel y además subrayan rasgos de estilo que perfilan con acierto a la directora. Ben Kingsley opina que a Coixet "le gusta la moderación, no exagerar, busca la sinceridad en vez de que luzcas". Penélope Cruz apunta que "crea ambiente, vida, comunicación; no es sólo encanto visual sino que tiene mucha sensibilidad. Mira al hombre con el corazón, también tiene una parte masculina que la hace más especial." Patricia Clarke destaca de la catalana: “Crea un ambiente de rodaje fácil. Es increíble cómo mezcla la fantasía y lo real." Dennis Hooper, otro actor norteamericano veterano, comenta: “Es muy buena, ella maneja la cámara. Tiene sensibilidad, y sentimiento maternal que resulta reconfortante. Rueda pocas tomas, deja que los actores trabajen y todo fluya."

La última película Mapa de los sonidos de Tokyo es un thriller, que centra el argumento en una dependienta de una pescadería que lleva una doble vida como asesina a sueldo. En este filme la catalana vuelve a componer el guión. Vuelve a dirigir a actores reconocidos como Rinko Kikuchi (Babel) como Riu, o Sergi López en el papel de David (El laberinto del Fauno). Mientras se redacta este artículo, la cinta ha sido elegida en el certamen de Cannes en la edición de mayo de este año junto a 
Los abrazos rotos de Pedro Almodóvar. No hay más que añadir, porque está claro que la directora catalana se ha labrado por mérito propio un lugar entre los grandes en el ámbito internacional.

\section{El caso de la adaptación de El animal moribundo a la película Elegy (2008)}

Es interesante conocer algunos datos biográficos sobre el escritor Philip Roth, autor de El animal moribundo. Se trata de un escritor estadounidense de origen judío, conocido sobre todo por sus novelas, aunque también escribiera cuentos y ensayos. Ha recibido muchos premios por su obra. Fue profesor e impartió escritura creativa en la Universidad de Iowa y en Princeton. El animal moribundo corresponde a la tercera entrega de una trilogía dedicada al personaje de David Kepesh. Se trata de una novela que resulta corta, pues cuenta con ciento veinte páginas. Elegy es la quinta adaptación al cine de algunas de sus novelas.

El título para este largometraje es Elegy en inglés, que significa "elegía” en castellano, en vez de "El animal moribundo", el título de la novela que ya era más conocido sacado de un poema de Yeats: “Consume mi corazón; enfermo de deseo/Y atado a un animal moribundo/ No sabe lo que es" (Roth, 2009:83). El título coincide con el punto de vista de la narración predominante: el profesor David Kepesh. Con ecos machadianos el protagonista cuenta en esta cinta su historia de amor con una alumna, Consuelo Castilla, con retrospectiva melancólica porque ella, aunque es mucho más joven, fallece antes que él.

Es diferente y curiosa la riqueza narrativa de la novela narrada también por David donde avanza de la narración al soliloquio, y luego al diálogo con el lector como signo de soledad porque no tiene a nadie más al que acudir al final del relato, al que llega a interpelar: “¿Cómo me sentí? Lo que más me hizo padecer aquella noche fue 
imaginarla sola y presa del pánico en la cama. Pánico a la muerte. ¿Y qué ocurrirá ahora? ¿Qué crees tú?”

El prisma de la película muestra la interpretación de la directora catalana sobre el libro que le fue leído por el propio escritor. Para la adaptación Coixet considera que ha cogido la esencia de la realidad del protagonista. Se trata de un hombre que a los sesenta años se enamora y sufre los rigores de los celos. Entre otras dificultades el profesor Kepesh se siente incapaz de verbalizar el amor que siente por Consuelo (Elegy DVD, 2008, Documental).

bea2.gif (24004 bytes)

En efecto, la directora ha centrado la historia en la relación entre David y Consuelo donde ha representado casi todos los momentos importantes. Sin embargo, se descubre una transformación de esta relación porque ha resaltado la cara del amor que ambos sienten y ha mitigado el carácter lujurioso del profesor. Se entiende más la obsesión que manifiesta por Consuelo porque el personaje vive abrumado por su llegada inminente hacia la decrepitud. El tono narrativo de David en la película resulta más humano que en la novela porque en el relato utiliza mucho la ironía y el sarcasmo de forma que ensombrece la realidad de forma negativa. Además ha omitido otros escarceos eróticos con otras alumnas como Miranda (Roth, 2008: 15), Jean Wyatt (Roth, 2008: 48), otras mujeres (Roth, 2009: 87), otras acciones sexuales y descripciones obscenas explícitas. También aparecen las historias adúlteras de otros dos amigos escritores George y Austin (Roth, 2009: 89).

Asimismo descarta otros discursos intelectuales que refuerzan la postura libertina del protagonista que aparecen en la novela, pues considera una relación estable como una pérdida en definitiva del hedonismo egoísta que enaltece, y por último, de la libertad: “Al cabo de un tiempo, ni siquiera sé por qué estoy desesperado. ¿Sus tetas? ¿Su alma? ¿Su juventud? ¿Su mente simple? Tal vez es algo peor que eso, tal vez 
ahora que estoy cerca de la muerte, también ansío en secreto no ser libre" (Roth, 2009: 85).

En la novela se descubre más las motivaciones libidinosas del profesor que se siente seguro de atraer a sus alumnas por su prestigio profesional, su fama debido a la aparición en los Medios y su cultura superior: "la cultura es importante y estupenda, como ninguna cosa que ella conozca." (Roth, 2008: 13). En el caso de Consuelo no la considera inteligente. Con ironía apunta: “No olvides que Consuelo no es la chica más inteligente del mundo" (Roth, 2008: 110).

La película omite las posturas políticas como la crítica contra el castrismo que realiza Consuelo (Roth, 2009:113-118) o la crítica con la que David satiriza a la clase tradicional cubana inmigrante o los republicanos (Roth, 2009: 43). Hay otros elementos añadidos en la película. La perspectiva de que la belleza está en los ojos de quien la mira, o la referencia a Otelo por los celos de David.

La representación espacial minimalista en espacios sobrios, vacíos y grises de los recuerdos de David sobre Consuelo es otro de los aciertos de la puesta en escena de Coixet. La escenografía se ha subordinado a centrar la atención en los diálogos y pretenden acomodar la intimidad de los personajes. Se destacan a su vez notas teatrales en la puesta en escena porque se respetan los espacios y los encuentros entre personajes, no hay interferencias de otros personajes, ni predominio de lo visual. Utiliza planos largos en la descripción, en cambio prefiere los diálogos por pares, de frente, de perfil con planos medios y cortos. Vuelve al uso del simbolismo cuando filma que unas hojas se caen, una vecina mayor que cotillea por la ventana, él piensa y revela unas fotos. Este uso simbólico sirve para representar la transición temporal como en la cinta A los que aman con la caída de unas granadas para representar el amor añejo del doctor por su amiga de la infancia. 
Se descubren variaciones en las subtramas. La relación entre padre e hijo está desarrollada en la cinta a través de muchas escenas, está mucho más materializada que en el libro donde sólo está sugerido. El aborto de Carolyn de la relación con Kepesh no aparece en el libro y su uso se estima que sirve para dramatizar la vida de los dos. En el libro se describe la vida solitaria de Carolyn pero se pone el acento en que busca amantes entre los inmigrantes jóvenes y que trabaja tanto que no dispone de tiempo para mantener una relación estable con una pareja, y menos una familia. En la parte final de la relación con Consuelo se busca también una mayor dramatización: en la cinta de Coixet es una invención los diálogos, la sesión de fotos con Consuelo, y la escena final en la que se queda David acostado con Consuelo en el hospital. En la cinta se representa una evolución en madurez de los personajes que no se pretende tanto en el libro que representa más el vacío de vidas hedonistas que no han sabido cultivar un amor auténtico.

Dedica muchas páginas a describir el origen de su relación con las alumnas que protagonizaron la revolución sexual en su facultad como su amante Carolyn, que es también origen de su divorcio y del odio que siente su hijo por él. Justifica su comportamiento sexual promiscuo con muchos argumentos, reprocha la educación que le dieron sus padres judíos respecto al sexo, se mofa del puritanismo y explica el contexto histórico de la revolución sexual y cultural de los años 70 (Roth, 2008: 4275). De alguna manera, todo esta parte defiende el punto de vista que ha pretendido mantener hasta que se da cuenta que se ha enamorado de Consuelo, que ha pasado tres años de depresión por ella, y que al final cuando ella, enferma de cáncer, acude a él, no la puede abandonar en el hospital y tratar como al resto de las mujeres: "Pero debo hacerlo. Alguien ha de estar con ella. Ya encontrará a alguien. Está aterrada. Me voy. Piensa en ello. Piénsalo. Porque si vas, estás acabado" (Roth, 2009: 120). 


\title{
5. Comparación del contexto social presentado en Mi vida sin mí (2003) y Elegy (2008)
}

\author{
* Parte de Antonio M. Conesa Nieto
}

Se realiza a continuación un recorrido histórico de la sociedad norteamericana con el fin de centrar más el comentario de la sociedad contemporánea en las dos cintas. La sociedad norteamericana ha sufrido grandes cambios desde que el hombre europeo apareció por esas tierras y sometió a la población autóctona (tribus indias), pues, ha pasado por las distintas fases coloniales, hasta convertirse en estandarte y precursora de las ideas de la sociedad occidental y del mundo global.

Este proceso tuvo lugar durante siglos, pero fue a partir de la primera mitad del siglo XX, cuando debido a una serie de circunstancias a nivel mundial, Estados Unidos obtuvo los más importantes avances en todos los campos entre los cuales la sociedad ocupa un lugar primario debido a sus grandes logros, algunos fueron fracasos, y al trasvase de ideas que esto produjo a nivel mundial.

De este modo podríamos dividir este proceso de la sociedad americana en cuatro fases diferencias y a la vez entrelazadas entre si; serian en primer lugar el periodo conocido como Belle Epoque; en segundo lugar los felices años 20, en tercero la sociedad de consumo y por último el nuevo orden mundial.

Esta sería una división general del desarrollo y entendimiento de la sociedad norteamericana, por lo tanto a continuación desarrollaremos una breve explicación de cada una de las fases y de este modo daremos contexto y comparación a las películas Elegy y Mi vida sin mí de la directora Isabel Coixet. 


\subsection{Belle Epoque}

Se denominó Belle Epóque al período que abarca desde fines del siglo XIX hasta la Primera Guerra Mundial (1914), caracterizado por un transitorio bienestar económico, una gran euforia y optimismo, en las clases altas y medias de los países industrializados de Europa y algo en los EE.UU. Esto fue producto de los avances tecnológicos y científicos de la época.

El crecimiento de las ciudades fue cambiando los hábitos de la gente, abarcando todas las clases sociales. El descanso dominical, la reducción de la jornada laboral y la posterior incorporación del Sábado Inglés (media jornada), crearon un tiempo libre difícil de ocupar.

Miles de personas, gracias al ferrocarril, se trasladaban los fines de semana en excursión a otras ciudades, al campo o al mar. En los sectores populares, el tiempo libre era todo un problema: no tenían dinero pata consumir o para gastar en paseos. El alcohol, el juego y las peleas eran los entretenimientos más difundidos.

Frente a esto, los grupos religiosos, los colegios y otras instituciones fomentaron la práctica de juegos en los que se realizaran esfuerzos físicos y fueran vistosos para el público: surgieron así los espectáculos deportivos, el fútbol y el rugby en Inglaterra; el básquet, el béisbol y el fútbol americano en los Estados Unidos. También fueron populares el box, las carreras de caballos y el ciclismo. Todos estos deportes fueron rápidamente aceptados en todo el mundo.

Mientras tanto, los sectores medios y altos disfrutaban del teatro, la música, las grandes exposiciones o simplemente salían de compras para estar a la última moda. Otro cambio importante fue la valoración de la educación: ahora no sólo era más accesible estudiar, sino que constituía una forma de ascenso social. 
Esta época de esplendor y optimismo se pudo ver simbolizada en el barco mas grande, lujoso y rápido del mundo: el Titanic, cuyo hundimiento, dos años antes de la guerra (1912), anticipó el fin de esta época de esplendor.

\subsection{Años 20}

Cuando finalizó la Primera Guerra Mundial, Estados Unidos se había convertido en acreedor de las grandes potencias europeas y aparecía como gran potencia mundial. La deuda contraída por Europa con los Estados Unidos ascendía a unos 7 mil millones de dólares, a los que se sumarían, algo más tarde, 3 mil millones más para la reconstrucción del viejo continente.

En marzo de 1920 el Senado norteamericano se opuso a los acuerdos alcanzados por el presidente demócrata Woodrow Wilson en Europa, y rechazó el Tratado de Versalles y el Pacto de la Liga de las Naciones. Comenzaron las presidencias republicanas: Harding (1921-1923), Calvin Coolidge (1923-1929) y Hehert C. Hoover (1929-1933). Éstos adoptaron una política aislacionista, que durante veinte años mantuvo a Estados Unidos alejado de los acontecimientos europeos y del Extremo Oriente.

La población norteamericana, de acuerdo con esta política, deseaba tener el menor compromiso posible con Europa y con los inmigrantes entre 1920 y 1924, la inmigración disminuyó notoriamente. El nacionalismo, alimentado por el conflicto, continuó terminado éste, y potenciado por la Revolución Rusa, se dirigió contra los políticos reformistas y los dirigentes y militantes sindicales. Estos últimos estaban, en su mayoría, integrados por inmigrantes que no eran considerados auténticos norteamericanos Una breve crisis (1918-1920), acompañada \& numerosas huelgas, aumentó miedos y rencores. 
Profesores universitarios y realizadores cinematográficos fueron objeto de todo tipo de agresiones y denuncias. Muchos inmigrantes fueron deportados. La comunidad negra fue hostigada El Ku Klux Klan (organización secreta racista terrorista) no sólo actuó en el sur de los Estado Unidos (donde había sido creada a la finalización de la guerra de Secesión), sino en el oeste, y su víctimas fueron, además de personas de raza negra, miembros de la comunidad judía y católica.

Sin embargo, la década de 1920 en los Estados Unidos no es recordada por nada de esto. Ha ingresado en el imaginario colectivo, no sólo de los norteamericanos, sino de latinoamericanos y europeos, por la ley seca, los gángsteres, las polleras por la rodilla, el jazz, el charlestón, las películas de Hollywood, las estrellas del espectáculo, el béisbol, los ídolos del box y el desborde de una vida urbana y alocada. Los años 20 dieron comienzo a la presencia del consumo masivo en los productos culturales. Nacía la cultura de masas.

El 17 de octubre de 1920 fue prohibido el consumo de alcohol. La llamada ley seca hizo millonarios a muchos hombres que se dedicaron a la venta clandestina de alcohol y socavó la autoridad del gobierno norteamericano. En realidad fue una concesión del gobierno a la población de las pequeñas ciudades del campo, que no participó de la prosperidad general. El sur rural, sosteniendo los antiguos valores de la americanidad, culpaba al alcohol de numerosas enfermedades, desde la parálisis hasta la epilepsia.

Adhirieron grupos feministas y las iglesias protestantes. En las grandes ciudades, beber ilegalmente se convirtió en una aventura, y las bandas de gángsteres lo transformaron en un floreciente negocio. 
Fue la década de la publicidad, el automóvil, la energía eléctrica y el confort generalizado. En el avance de la publicidad, mucho tuvo que ver la radio y los diarios populares que, en formato de tabloides, multiplicaron sus ventas.

En 1919, aparecieron los programas comerciales, con el fin de estimular la venta de aparatos de radio. En ese año ya funcionaban 606 estaciones y circulaban 6.750 .000 automóviles. Diez años después, los automotores se cuadruplicaron y había un vehículo cada cinco personas. Comenzaron las ventas a crédito y, hacia fines de la década, el 60 \% de los vehículos eran vendidos en cuotas.

Los efectos de la producción automovilística se extendieron a toda la economía. Esta industria requería de gran cantidad de acero, plomo, cuero y textiles para los interiores del automotor.

La política de créditos baratos facilitó las compras, pero el dinero en circulación se duplicó, hizo posible la emisión de nuevas acciones y la especulación en el mercado inmobiliario.

Los sistemas de ventas frieron modificados para poder satisfacer una demanda en aumento. Aparecieron las cadenas de almacenes especializados en la venta de productos alimenticios y farmacéuticos. El aumento del número de automóviles posibilitó la compra en los centros comerciales. Hacia 1929, la mitad de las ventas se hacían directamente y al contado. La oferta era variada y novedosa: refrigeradores, lavarropas, motocicletas, aspiradoras. Hollywood, con sus películas, publicitó la vida confortable y urbana.

La expansión del sector servicios multiplicó el empleo urbano y determinó el crecimiento de las ciudades. Éstas lo hicieron para arriba, gracias al ascensor y a las estructuras de acero. La abundancia de rascacielos evidenció la existencia de un 
extraordinario desarrollo económico. En 1929 finalizó la construcción del edificio Chrysler, de 77 pisos, en Nueva York, y en 1931 fue inaugurado el Empire State, de 102 pisos, que, con 381 metros de altura, pasó a ser el edificio para viviendas u oficinas más alto del mundo.

\subsection{La sociedad de consumo}

Como consecuencia de la implantación del llamado Estado de bienestar, a partir de fines de la Segunda Guerra Mundial, importantes sectores sociales de los países industrializados aumentaron, considerablemente, el poder adquisitivo. Para mantener esa situación de mejoramiento salarial y de cobertura social, era necesario acrecentar la producción y, en forma paralela, el consumo para que se pudiera absorber todo lo fabricado. Así aumentarían las ganancias de los industriales que, a su vez, dispondrían de más capitales para seguir mejorando la capacidad adquisitiva de las clases medias y bajas, formando un círculo en el cual todos los elementos debían conservar el equilibrio.

Todo esto se hizo posible gracias a los adelantos tecnológicos. El mejoramiento salarial se dio a partir de las negociaciones entre los sindicatos y las organizaciones patronales, y asegurando las mayores ganancias a los empresarios. Para sostener este nivel de vida, era necesario aumentar el consumo, aun de productos superfluos que comenzaron a ser publicitados como imprescindibles.

A fin de lograr ese objetivo, fue creado en los Estados Unidos un nuevo estilo de vida, que comenzó a difundirse como el american way of life (estilo de vida americano). Para ello, se utilizaron dos elementos: la publicidad y la disminución de la calidad de los productos, con el fin de que tuvieran menor vida útil y por lo tanto, fuera necesario reponerlos más rápidamente. 
Esta nueva forma de vida se basaba en el consumo de todo tipo de artículos, como uno de los principales caminos para la realización individual de los seres humanos. Se dejaban en segundo plano muchos de los valores culturales sostenidos hasta entonces, como el crecimiento intelectual y espiritual.

Las características de ese "estilo' fueron - además del consumismo - la exageración, la ostentación de la riqueza y la grandiosidad, reflejadas en todos los órdenes. La industria automotriz norteamericana, por ejemplo, se diferenció de las demás por el enorme tamaño de sus vehículos y por su mayor potencia. Los automóviles Impala, inmensos en tamaño, se convirtieron en el símbolo de la riqueza de los años 60 . Se creó, de este modo, una notoria influencia y hasta dependencia cultural, pues el resto de los países estuvieron influidos por la moda y las preferencias norteamericanas, más allá de sus propias tradiciones o idiomas.

Después de la Segunda Guerra, el avance tecnológico (en electrónica, física y química), la mayor disponibilidad de mano de obra - producto de la paz y del aumento demográfico- ocasionaron un gran incremento de la producción industrial. Para mantener y aumentar el nivel de ganancias de los empresarios, fue necesario elevar el consumo, para lo cual se incorporó a los sectores medios y bajos en el mercado consumidor de productos antes reservados a las clases privilegiadas, tales como, electrodomésticos, automóviles, etc.

Además de aumentar el consumo, las mejoras en el nivel de vida de los obreros hacían disminuir los reclamos y los alejaban de los posibles conflictos sociales. A este modelo basado en el consumo masivo se lo denominó sociedad de consumo. Dos elementos fundamentales ayudaron a instalar el consumismo: la publicidad y las ventas a crédito. 
Se estimulaba a través del cine, la radio, la televisión, de los diarios y de las revistas, el deseo por acceder a un mundo ideal y fantástico, al cual sólo se ingresaba comprando determinadas "marcas" de productos. Para triunfar en la vida, había que manejar tal automóvil, beber determinada gaseosa o vestir la ropa de los famosos. Incluso, las manifestaciones artísticas, como la música, el cine, el teatro o la literatura, eran impuestas por la propaganda de las empresas discográficas, las distribuidoras cinematográficas y por las empresas teatrales o editoriales. Había nacido la cultura de masas, en la que era más importante la difusión que la creación artística en sí misma. Tenía más valor lo más conocido que lo más creativo o mejor producido. Prevalecía lo comercial sobre lo artístico.

A partir de los años 50, la modernización socioeconómica comenzó a expresarse claramente en el arte, la literatura y en otras manifestaciones culturales. A su vez, la expansión de los denominados medios masivos de comunicación, implicó una nueva y compleja relación entre las diferentes culturas. Sobre todo, porque el poder político y económico de los países centrales también iba a mostrarse en una capacidad, hasta ese momento impensable, de difundir sus valores culturales a otros pueblos. A su vez, en el interior de cada sociedad, también existían determinados valores predominantes, es decir, un cuerpo de ideas coherentes que explicaban una particular visión del mundo e impregnaban la vida social y cultural de una comunidad. Y en toda sociedad, paralelamente a esa cultura dominante, surgieron grupos que se planteaban otros valores, otras ideas sobre lo que estaba bien o estaba mal, y que cuestionaron los valores los modos de relación y el sistema político de una época.

Esos grupos comenzaron a surgir en los años de posguerra, al calor de la urbanización y del crecimiento de la matrícula estudiantil en todos los niveles. Fueron movimientos que cuestionaron la forma en que estaba ordenada la sociedad y que se pronunciaron por alternativas de vida distintas de las formas en que habían 
sido educados por sus mayores. Estas voces fueron, a veces, subcultura que expresaron a subgrupos de la sociedad, como pueden ser los jóvenes que utilizaban una manera particular de vestirse, hablar, etc., o auténticas contraculturas, es decir en corrientes de opinión que planteaban valores contrarios a los predominantes en la sociedad de la que eran parte.

La complejidad de este proceso de intercambio cultural estuvo dada, también, porque los modernos medios de difusión fueron parte de la Guerra Fría. Estos medios, controlados por los países centrales, comenzaron a irradiar a todas partes del mundo sus valores y hábitos culturales, como los que se correspondían con el mundo occidental y cristiano frente al ateísmo socialista. Otro importante elemento de propaganda fueron los comics, donde héroes dotados de poderes sobrehumanos como Superman o el Capitán América - lograron proteger al mundo occidental de la constante amenaza de sus enemigos.

Frente a esta influencia cultural, marcada y guiada por la sociedad de consumo, nacieron en la postguerra pensamientos alternativos a los dominantes, es decir verdaderos movimientos contraculturales: todos dieron muestras de inconformismo, rebeldía y resistencia a la imposición cultural a Li que se sentían sometidos.

La denominada cultura beat se originó en los Estados Unidos y fue la expresión de una generación que no creía en los mitos de los adelantos científicos que habían producido la mecanización, ni en la adoración del dinero como medio de satisfacción. Allen Ginsberg y Jack Kerouac fueron - a través de poesías y cuentos que transitaban en revistas subterráneas (underground) sin circulación comercialtípicos representantes de una búsqueda por separarse de una sociedad que consideraban arbitraria y falsa. En ella los hombres - afirmaban - habían perdido la capacidad de comunicarse y vivir, producto de los bombardeos publicitarios que 
alentaban únicamente la superficialidad del confort: el auto, la casa, el televisor, etcétera. Para manifestar su disconformidad, alentaron la resistencia al consumo.

En Europa, junto al desarrollo del Estado de bienestar que daba lugar a la "sociedad del ocio", la resistencia cultural se expresó también en el terreno filosófico: autores como Herbert Marcuse o Jean Paul Sartre adquirieron notoriedad en los 50, aunque sus libros y figuras fueron célebres en los 60. La búsqueda de lo auténticamente latinoamericano fue parte de ese pensamiento alternativo, y la crítica apuntó a padecimientos de sus habitantes por parte de dictaduras o regímenes que permitían y alentaban el despojo económico, acompañado de la destrucción de la identidad cultural propia. Julio Cortázar, Mario Vargas Llosa, Alejo Carpentier y José María Arguedas fueron - entre otros- parte de esa generación que, en sus novelas, expresaron la resistencia y alternativa cultural en Latinoamérica.

\subsection{Nuevo orden mundial}

Durante la Guerra Fría, la humanidad vivía con el temor de que en cualquier momento se desataría una conflagración con el uso de las armas nucleares, por parte de cualquiera de las dos potencias: la Unión Soviética o Estados Unidos. Sin embargo, no parecía darse cuenta de que, en los últimos 30 años, nuevos peligros están acechando a la vida de los habitantes del planeta.

Unos de ellos son la utilización y explotación indiscriminada de los recursos naturales y la contaminación del medio ambiente, que se agravan por la condición de no imponer limitaciones al libre comercio. El mensaje de la $\mathrm{OMC}$, durante la reunión ministerial en Doha, fue claro: “No a la protección ambiental si ésta significa restricción comercial." Con la expansión de los mercados se ha incrementado el uso de materia prima de origen animal, vegetal y mineral para la elaboración de los productos, sin importar destruir selvas, provocar sequías y hambrunas, desecar y 
contaminar ríos y lagos, producir nuevas enfermedades a hombres y animales, erosionar la tierra cultivable, sumir en la miseria a incontables poblaciones, ni contaminar el aire con desechos tóxicos.

El paisaje urbano y rural ha sido cambiado por el hombre a causa del cultivo agrícola organizado. Las montañas han sido cortadas para construir carreteras y vías de ferrocarril. Los bosques y praderas han desaparecido para construir casas. Además se han desviado ríos y se han edificado industrias contaminantes.

Es imposible tratar de conservar la naturaleza como está, porque debido a las necesidades propias del hombre actual se vuelve necesario cambiarla. Para juzgar lo que sucedería en el futuro, debemos basarnos en la experiencia acumulada. La degradación del medio ambiente es un fenómeno global. Los gobiernos no han creado estrategias adecuadas para proteger el medio ambiente, ni se ha educado ni concienciado adecuadamente a la población para solucionar tales problemas. Existen organismos no gubernamentales, como Greenpeace, que se preocupan por evitar la tala inmoderada de árboles, la contaminación del agua y el aire, el uso de aerosoles e insecticidas, la producción de alimentos transgénicos, la caza inmoderada de animales en peligro de extinción, etcétera; sin embargo, no se toma en cuenta con la seriedad que se necesita.

Se trata de un problema prioritario de seguridad nacional que debe atenderse considerando su importancia vital. Por otra parte, los Estados poderosos quieren el control y la explotación de los países ricos en recursos naturales, lo cual ha generado conflictos bélicos, que, a su vez, también aumentan la destrucción del medio ambiente, y la contaminación en tierra, ríos y mares.

Otro de los grandes problemas que forma parte de la vida cotidiana es el narcotráfico. Su presencia corrompe a autoridades civiles y militares, sumiendo en la 
drogadicción y la dependencia a millones de niños, jóvenes y adultos. Se ha convertido en un gran problema social que destruye física y mentalmente y provoca delincuencia, trastornos en la educación y en la producción, por inasistencia a los centros de trabajo, así como problemas familiares.

Males de nuestro tiempo son el desempleo, la explosión demográfica y los trastornos psicológicos como el estrés y la depresión, provocados por cuestiones tanto económicas como sociales. El hombre se preocupa más por producir y poseer cosas que por pensar y buscar satisfactores para su crecimiento espiritual y emocional. Vivimos en una sociedad de consumo donde la riqueza está mal repartida; donde se manipula, se controla y se deshumaniza al hombre. Una sociedad que tiene un Big Brother que vigila, que dice lo que se tiene qué hacer.

\subsection{Contexto y comparación de las cintas: Mi vida sin mí y Elegy}

La comparación contextual entre ambas cintas resulta ser diametralmente opuesta desde el punto de vista social, debido a la controvertida y variopinta sociedad norteamericana, consecuencia a su vez de la mezcla de las fases anteriormente descritas.

La película Elegy nos transporta a un mundo refinado, culto y muy europeo; en el caso de la otra cinta, Mi vida sin mí, nos encontramos con la parte más fracasada de la sociedad norteamericana. Este fracaso no puede considerarse como un fracaso solamente personal, sino general del sistema, desde que las bases del mismo comenzaron a fraguarse siglos atrás.

La sociedad de consumo y el estado de bienestar son conceptos que en Estados Unidos pueden tener varias lecturas; por una parte son las bases mismas del sistema social norteamericano llevadas hasta el límite, es decir un consumismo y 
materialismo exagerado; frente a las agudas y conocidas bolsas de pobreza que se dan en esa misma sociedad.

De todo esto, además, surge otra realidad y es el hecho de que la sociedad norteamericana esta tan sumida en ese materialismo que salvo ciertas elites y sectores, la cultura general no es el fuerte de dicha sociedad. Precisamente esto es un punto que llama poderosamente la atención tras el visionado de la películas; por una parte en Elegy nos encontramos de pleno con ese mundo erudito y muy europeizado donde el gusto por la pintura, la literatura y el teatro son constantes en la vida del protagonista y frente a todo esto, tenemos a la protagonista de Mi vida sin mí, que representa la antitesis de lo mencionado con anterioridad.

Esta dicotomía de la sociedad americana es producto, como hemos dicho anteriormente, de la mezcla de varios factores desde siglos atrás que a su vez provocan en el presente grandes desigualdades sociales.

Las desigualdades sociales en Norteamérica son más pronunciadas que en Europa, mientras en Europa la sociedad sigue un curso más lineal, aunque hay también grandes desigualdades, en Estados Unidos nos encontramos con más irregularidades. La sociedad norteamericana se basa en tener una casa, un coche o varios y todos aquellos bienes materiales que creen imprescindibles para la vida; una vez cubiertos esos objetivos, lo demás es superfluo, de ahí viene el bajo nivel cultural de los norteamericanos. Todo esto se agudiza más si el nivel económico de la persona es bajo, es el caso de la protagonista de Mi vida sin mí, pero con una salvedad y es que, ella es de esas personas a las que la vida no les ha dado ninguna oportunidad, aunque lucha por salir de ese ostracismo pero con mínimos resultados. En esta cinta se nos muestra esa parte de la sociedad americana que vive en caravanas con escasos recursos económicos, muy lejos de ese ambiente cosmopolita que en Elegy se nos presenta. Pero también debemos matizar, el hecho de que en Estados Unidos el 
cosmopolitismo se puede entender desde dos puntos de vista distintos, esta el cosmopolita que busca lo nuevo, lo diferente y que vive en esas atmósferas cool, frente al que viviendo de la misma manera, busca algo más, es el caso del protagonista de Elegy, que si muestra el gusto por la cultura, el saber y el mundo interior.

Siguiendo esta estela los norteamericanos ven en Europa ese mundo de rancio abolengo y se sienten de un modo u otro unidos a él, por eso por parte de las elites más eruditas se da ese gusto por la cultura porque son conscientes que ellos no tienen una historia tan vasta como la europea. En cambio, el grueso de la sociedad americana se lamenta de no tener una realeza y familias nobiliarias de ahí que se inventasen literalmente el star system y el mundo de las celebrities. Todo esto nos hace reflexionar acerca de lo frívola y banal que puede llegar a ser esa sociedad.

Las consideraciones finales hacia las películas, podrían ser que en ambas cintas observamos los polos opuestos de la sociedad norteamericana, pero que a su vez están magníficamente representadas tanto por sus protagonistas como por el ambiente que las rodea. Es el paralelismo entre lo erudito y lo vulgar.

\section{Conclusiones}

Se vuelve a descubrir en esta cinta el gusto de Coixet por la descripción psicológica del interior de los personajes en un tono positivo y con una evolución hacia la madurez como muestra en anteriores cintas como A los que aman, Mi vida sin mí o La vida secreta de las palabras. La vivencia del amor es un andén al que se llega por encima de cualquier obstáculo externo o interno, o como en este caso a pesar de la vida de hedonismo del profesor de literatura. Estos factores se vislumbran como constantes en la directora catalana. 
A pesar de ser fiel al relato, se detecta transformaciones relevantes que lo convierten en un producto nuevo al estilo de la cineasta, pues evita centrarse en la vida libertina del protagonista y se centra en la relación amorosa que mantiene con su joven alumna. A su vez refleja más la vida vacía del profesor, las relaciones negativas con su amante, su hijo y se subraya más la soledad en la que acaba, pues su amigo acaba falleciendo. Es un don Juan desacreditado, patético que acaba por suscitar compasión a los espectadores.

La comparación entre la situación social y los estatus de los protagonistas de Mi vida sin mí y Elegy muestra el mérito de un conocimiento profundo de la cineasta de la sociedad norteamericana a la que ha estudiado por su carrera de Historia y donde ha vivido. Coixet goza de ser una director española capaz de reflejar las capas sociales tanto medio altas como humildes del american way of life como si se tratara de una nativa.

\section{Bibliografía}

AGUILAR, Carlos, Guía del cine español, Madrid, Cátedra, 2007

BORAU, José Luis, Diccionario de cine español, Madrid, Alianza, 1998

BOSCH, A., Historia de EE.UU., 1776-1945, Editorial Crítica, Barcelona, 2005

BARROSO, Miguel Ángel, Cine español en cien películas, Madrid, Jaguar, 2002

CAPARRÓS LERA, Jose María, Historia crítica del cine español, Barcelona, Ariel Historia, 1999 
CASTILLÓN, Juan Carlos, Extremo occidente. Una historia personal de los Estados Unidos, Debate, Barcelona, 2008

CASTRO DE LA PAZ, José Luis, Pérez Perucha, Julio y Santos Zunzunegui (eds.), La nueva memoria: historia(s) del cine español (1939-2000), A Coruña, Vía Lactea, 2000

EVANS, Peter William, Spanish cinema. The auteurist tradition, NY, Oxford Univerity Press, 1999

GUBERT, Roman, Historia del cine, Madrid, Cátedra, 2007

JONES, M. A., Historia de Estados Unidos, 1607-1993, Ediciones Cátedra, Madrid, 2001

MAUROIS, André y LUZURIAGA, Maria Luisa, Historia de los Estados Unidos, Buenos Aires, Losada, 1945

MERINO, Azucena, Diccionario de mujeres directoras, Madrid, ediciones JC, 1999

RENTERO, Juan Carlos, Diccionario ilustrado de directores, Madrid, ediciones JC, $3^{\mathrm{a}}$ ed, 2002

PÉREZ PERUCHA J., Antología crítica del cine español, 1906-1995: flor en la sombra, Madrid, Cátedra, 1997

RODRÍGUEZ MERCHÁN, Eduardo, El cine español de la democracia (1977-2000) en Un siglo de cine español, Cuadernos de la Academia, nº $3^{\text {a }}$ ed., Academia de Ciencias y Artes cinematográficas de España, Madrid, 2000 
ROTH, Philip, El animal moribundo, Madrid, Debolsillo, 2008

PAYÁN, Miguel Juan, El cine español actual, Madrid, Ediciones JC, 2001

PROCACCI, G., Historia general del siglo XX, Editorial Crítica, Barcelona, 2005

PUIGDOMENECH, Jordi, Treinta años de cine español en democracia, Madrid, JC, 2007

SÁNCHEZ NORIEGA, José Luis, Historia del Cine, Madrid, Alianza Editorial, 2002

SALDIVAR, César, Una mirada al cine español, Madrid, Espasa, 2000

SEGUIN, Jean Claude, Historia del cine español, Madrid, Acento, 1999

WOODS, Thomas E. The politically incorrect guide to American history, New York, Regnery Publishing, 2004

Revistas

CAPARRÓS LERA, José María, La madurez del cine español. En: El noticiero de las ideas, octubre-diciembre 2001, Madrid, Editorial: Comerensa Prensa, pp.36-44

RODRIGUEZ MARCHANTE, E., El estado del cine español. En: El noticiero de las ideas, octubre-diciembre 2007, Madrid, Editorial: Comerensa Prensa, pp.36-44

Webgrafía

http://noticias.labutaca.net/category/genero/animacion/ [acc: 11.05.2009] 
http://us.imdb.com/name/nm0001426/ [acc: 11.05.2009]

http://www.imdb.com/name/nm0004851/ [acc: 11.05.2009]

Otros

Elegy, DVD, 2008 